\title{
Relação entre o diâmetro e histopatologia de bolsas de Fabrício de frangos de corte sob inspeção sanitária no estado de Santa Catarina
}

\section{Relationship between diameter and histopatology of bursa of Fabricius of broiler slaughtered under sanitary inspection in Santa Catarina state}

\author{
Fernanda Martinez Xavier Alves, ${ }^{*}$ Virginia Léo de Almeida Pereira, ${ }^{* *}$ Elmiro Rosendo do Nascimento, ${ }^{* *}$ Antônio Marco
} Pastore Guimarães, ${ }^{* * *}$ Davi de Oliveira Almeida, ${ }^{*}$ Rogério Tortelly****

\begin{abstract}
Resumo
Foram estudadas 128 bolsas de Fabrício de frangos de corte com idade entre 40 e 48 dias, vacinados contra a doença infecciosa da bolsa de Fabrício no décimo quarto dia de vida. As bolsas foram coletadas em um matadouro sob inspeção sanitária, e após mensuradas no bursômetro, foram acondicionadas em formol a 10\% para o processamento pela técnica habitual de histologia para inclusão em parafina e coloração pela hematoxilina-eosina, para exame histológico. Foram obtidos os seguintes resultados na escala do bursômetro, convertida em milímetros: $54(42,19 \%)$ frangos com bolsas de diâmetro 10mm (tamanho 3); 68 (53,12\%), com diâmetro 13mm (tamanho 4) e seis (4,69\%), com diâmetro 16mm (tamanho 5). As bolsas de Fabrício apresentaram os seguintes escores de lesões histológicas: escore 0, um caso; escore 1, três casos; escore 2, 25 casos e escore 3, 99 casos. As bolsas com os diâmetros 10 e 13mm, registraram grau de lesão mais grave, escore $3(p<0,001)$. Das bolsas de maior diâmetro, apenas um caso foi classificado com escore 3 . A maioria dos frangos de corte ao abate apresentou os menores tamanhos das bolsas de Fabrício, justificados pela observação das lesões microscópicas mais graves que promoveram a atrofia do órgão, o que pode comprometer a higidez da ave.
\end{abstract}

Palavras-chave: frango de corte, imunodepressão, bolsa de Fabrício, bursômetro, histopatologia.

\begin{abstract}
The present study evalueted 128 bursae of Fabricius of broiler aged between 40 and 48 days old, vaccinated against the infectious illness of bursa of Fabricius in the $14^{\text {th }}$ day of age (through drinking water). The bursae of Fabricius were collected in a slaughterhouse under sanitary inspection. After being measured in a bursometer, the bursal fragments were fixed with $10 \%$ phormol, in order to perform the processing by estabilished techniques and the consequent inclusion in parafin and stained with hematoxilin and eosin, in order to finish the histophatology. The measurement by bursometer revealed that 54 (42.19\%) chickens had presented 10mm of bursa of Fabricius diameter (size 3); 68 (53.12\%) of them with 13mm of diameter (size 4); and the other $6(4.69 \%), 16 \mathrm{~mm}$ (size 5). The bursae of Fabricius registered through histopatology analysis: score 0 , 1 case; score 1, 3 cases; score 2, 25 cases and score 3, 99 cases. The bursae of Fabricius whose diameter varying from 10 to $13 \mathrm{~mm}$ registered more serious injuries, score $3(p<0,001)$. Among the bursae of higher diameter, there was only a single case classified as score 3. The majority of the broilers presented smaller sizes of the bursae of Fabricius, by the observation of more serious microscopic injuries, responsible for the organ atrophy.
\end{abstract}

Keywords: broiler, immunodeppression, bursa of Fabricius, bursometer.

\section{Introdução}

$\mathrm{Na}$ avicultura industrial as doenças que afetam o sistema imune das aves domésticas representam um grande e crescente desafio para a boa performance produtiva desses animais. Por seu caráter insidioso, tais enfermidades geralmente levam à geração de efeitos deletérios, mais perceptíveis a médio e longo prazo, podendo acarretar falhas de vacinação, aumento nas taxas de condenação de carcaças

\footnotetext{
Programa de Pós-Graduação (Doutorado) em Medicina Veterinária, Área de Concentração: Higiene Veterinária e Processamento Tecnológico de Produtos de Origem Animal da Faculdade de Veterinária da Universidade Federal Fluminense, Niterói, RJ, Brasil.

** Departamento de Saúde Coletiva Veterinária e Saúde Pública da Faculdade de Veterinária da Universidade Federal Fluminense, Niterói, RJ, Brasil.

*** Fiscal Agropecuário, Ministério da Agricultura, Santa Catarina, SC, Brasil

**** Departamento de Patologia e Clínica Veterinária da Faculdade de Veterinária da Universidade Federal Fluminense, Niterói, RJ, Brasil. Autor para correspondência: Fernanda Martinez Xavier Alves. E-mail: fmmxa11@yahoo.com.br.
} 
e mortalidade, queda na conversão alimentar e na produção de ovos. A imunossupressão causa prejuízos econômicos, relacionados com todas essas perdas e gastos com medicamentos. A conseqüência mais evidente do estado de imunossupressão é um aumento da suscetibilidade a doenças infecciosas e parasitárias. As enfermidades virais indutoras de imunossupressão em galinhas são representadas pela Doença Infecciosa da Bolsa de Fabrício (DIB), pela anemia infecciosa aviaria, pelas reoviroses, e doenças neoplásicas, como a doença de Marek, leucoses aviárias e reticuloendoteliose (Montassier, 2000; Leffer, 2004). O efeito imunossupressor do vírus da DIB pode ser verificado também no matadouro, onde as perdas por caquexia, aeros-saculite, septicemia-toxemia e doenças de pele como celulite e outras afecções podem apresentar elevadas taxas de ocorrência (Rosales, 1999; Fallavena, 2001).

A bolsa de Fabrício é constituída de linfócitos incrustados em tecido epitelial, cujas dobras se estendem no interior do lúmen, onde se espalham folículos linfóides. O órgão funciona como um local de maturação e de diferenciação para as células do sistema formador de anticorpos. Seus folículos contêm mais de $90 \%$ de células $B$, sendo, assim, um órgão importante do sistema imune (Tizard, 1998). O estado de imunossupressão produzido pelo vírus da DIB pode estar relacionado com a destruição do tecido do parênquima da bolsa e por conseguinte, do local apropriado para ocorrer o desenvolvimento e as etapas finais da diferenciação destes linfócitos (Pope, 1991; Wilson et al., 1998).

Como forma de medir o diâmetro da bolsa de Fabrício e avaliar possíveis alterações no tamanho, pode-se usar o bursômetro. Trata-se de uma régua que possui orifícios numerados de 1 a 8 que medem, respectivamente, $4 \mathrm{~mm}, 7 \mathrm{~mm}, 10 \mathrm{~mm} ; 13 \mathrm{~mm}$; $16 \mathrm{~mm} ; 19 \mathrm{~mm} ; 22 \mathrm{~mm} ; 25 \mathrm{~mm}$ de diâmetro. A avaliação da bolsa de Fabrício deve ser criteriosa, não se forçando a passagem do orgão pelos orifícios, devendo passar normalmente; caso isto não ocorra, deve ser colocada no orifício seguinte (Bernardino, 2001).

Ley et al. (1983) verificaram, por meio da histologia, que a bolsa de Fabrício três dias após a inoculação do vírus da DIB apresentou folículos linfóides com escassez de células linfóides maduras, presença de heterófilos nos folículos e no espaço interfolicular edematoso, e necrose de coagulação com áreas císticas no folículo linfóide; no 7으 dia, houve um aumento de tecido conjuntivo interfolicular com a presença de macrófagos e inúmeros heterófilos, esses também presentes nos folículos; no 10 dia, havia restos de tecido conjuntivo, raros heterófilos, moderado número de células linfóides na cortical, enquanto a medular possuía eosinófilos e células vacuoladas; no 14 dia, os folículos estavam muito separados por células monucleares e tecido conjuntivo, havendo aumento de células linfóides na região cortical dos folículos e cistos na região medular. O epitélio da bolsa estava espessado e continha cistos.

Tanimura et al. (1995), em um experimento com três cepas diferentes do vírus da DIB, uma moderada e as outras muito virulentas, administradas via oral, em quatro grupos de 30 aves livres de patogenos, observaram, do primeiro ao terceiro dia após a inoculação, necrose no folículo linfóide, infiltrado inflamatório com presença de heterófilos e edema. Todas as cepas causaram severa atrofia na bolsa, pela depleção de células linfóides nos 13 dias em que duraram as observações.
Pereira et al. (2003) desenvolveram um estudo relacionando diâmetro na escala do bursômetro com escores histopatológicos em bolsas de Fabrício de frango de corte aos 28 dias de idade. Observaram que $76,96 \%$ das aves examinadas apresentavam medida do diâmetro de bolsa de Fabrício compatível com o uso de vacina. Pelo escore histopatológico, $62,76 \%$ das aves examinadas foram compatíveis com alterações microscópicas provocadas pela vacina intermediária. A maior diferença entre as duas técnicas ocorreu nos casos em que as aves apresentaram bolsa de Fabrício com escore histológico compatível com a doença, mas a maioria das bolsas havia sido incluída na categoria de diâmetro de bolsa compatível com vacina.

Pereira (2004), ao mensurar bolsas de Fabrício de 130 frangos de corte ao abate, constatou que 44 possuíam tamanho 3; 61, tamanho $4 ; 17$, tamanho 5 ; sete, tamanho 6 ; e uma tamanho 7. Neste trabalho, os frangos de corte analisados apresentaram lesões microscópicas graves na bolsa de Fabrício, o que favoreceu o aparecimento de outras enfermidades como: coccidiose, aerossaculite, lesão na cabeça do fêmur, pericardite e verminose, que depreciaram o peso, afetando a qualidade das aves ao abate.

Bolis et al. (2003) realizaram um trabalho com pintos comerciais divididos em quatro grupos (T1, T2, T3 e T4). O grupo T1 não recebeu vacina, nem desafio. Os demais grupos foram vacinados no primeiro dia de idade contra a DIB, e os grupos T3 e T4 receberam, aos 14 dias de idade, uma vacina forte e uma intermediária "plus", respectivamente. Com 21 dias de idade os grupos T2, T3 e T4 foram desafiados com uma cepa muito virulenta da DIB. Foi montado um escore de 0 a 6 para classificar as lesões microscópicas encontradas nas bolsas de Fabrício a partir do sétimo dia de idade. As aves dos grupos T2 e T4 tiveram lesões intensas na bolsa de Fabrício (acima do escore 4) dos 28 aos 42 dias de idade, o que demonstrou que não estavam protegidas contra a ação do vírus muito virulento.

Em função do exposto, o objetivo deste trabalho foi relacionar o tamanho das bolsas de Fabrício de frangos de corte ao abate, sob inspeção sanitária, aos achados histológicos.

\section{Material e métodos}

Foram estudadas 128 bolsas de Fabrício de frangos de corte com idade entre 40 e 48 dias, das linhagens Cobb ou Ross. As aves haviam recebido vacina contra doença infecciosa da bolsa de Fabrício uma única vez, aos 14 dias de idade, via água de bebida. As bolsas foram coletadas para estudo anatomopatológico em um matadouro, sob inspeção sanitária no estado de Santa Catarina. Após serem mensuradas no bursômetro, foram devidamente identificadas em ficha própria, acondicionadas em formol a $10 \%$ e, enviadas para o serviço de Anatomia Patológica Prof. Jefferson Andrade dos Santos na Faculdade de Veterinária da Universidade Federal Fluminense, onde foram processadas pela técnica habitual de histologia para inclusão em parafina e coloração pela hematoxilina-eosina, para análise histológica.

Foi criado um escore para análise histopatológica das lesões baseado naquele montado por Pereira (2004). Escore 0, sem lesão; Escore 1, edema, discretas hiperplasia e rarefação linfóide folicular e fluído acidófilo; Escore 2, infiltrado inflamatório, discreta atrofia de folículos, rarefação linfóide severa e necrose folicular e Escore 3, atrofia severa de folículos, cistos foliculares e epiteliais e fibrose. 
Nos casos de concomitância de lesões de escores diferentes, foram considerados os graus mais elevados. A relação entre o tamanho da bolsa de Fabrício e a intensidade da lesão (medida por escore) foi obtida pelo teste de qui-quadrado, com erro probabilístico $p<0,05$ (Thusfield, 1995).

\section{Resultados}

As 128 bolsas de Fabrício dos frangos estudados se encontram na Tabela 1.

Tabela 1: Distribuição da freqüência de frangos de corte por tamanho da bolsa de Fabrício (medida pela escala do bursômetro) e escores de lesão*

\begin{tabular}{cccccc}
\hline \hline \multirow{2}{*}{$\begin{array}{c}\text { Tamanho da Bolsa de } \\
\text { Fabrício na escala do } \\
\text { bursômetro }\end{array}$} & \multicolumn{4}{c}{$\begin{array}{c}\text { Escore de Lesões Microscópicas na Bolsa de } \\
\text { Fabrício de frangos de corte ao abate, } \mathrm{n}(\%)\end{array}$} & \multirow{2}{*}{ Total } \\
\cline { 2 - 5 } & 0 & 1 & 2 & 3 & \\
\hline $3(10 \mathrm{~mm})$ & $0(0,00 \%)$ & $0(0,00 \%)$ & $15(11,72 \%)$ & $39(30,47 \%)$ & $54(42,18 \%)$ \\
$4(13 \mathrm{~mm})$ & $0(0,00 \%)$ & $1(0,78 \%)$ & $8(6,25 \%)$ & $59(46,10 \%)$ & $68(53,12 \%)$ \\
$5(16 \mathrm{~mm})$ & $1(0,78 \%)$ & $2(1,56 \%)$ & $2(1,56 \%)$ & $1(0,78 \%)$ & $6(4,68 \%)$ \\
\hline Total & $1(0,78 \%)$ & $3(2,43 \%)$ & $25(19,53 \%)$ & $99(77,34 \%)$ & $128(100 \%)$ \\
\hline \hline
\end{tabular}

${ }^{*}$ Qui-quadrado, $p<0,001$

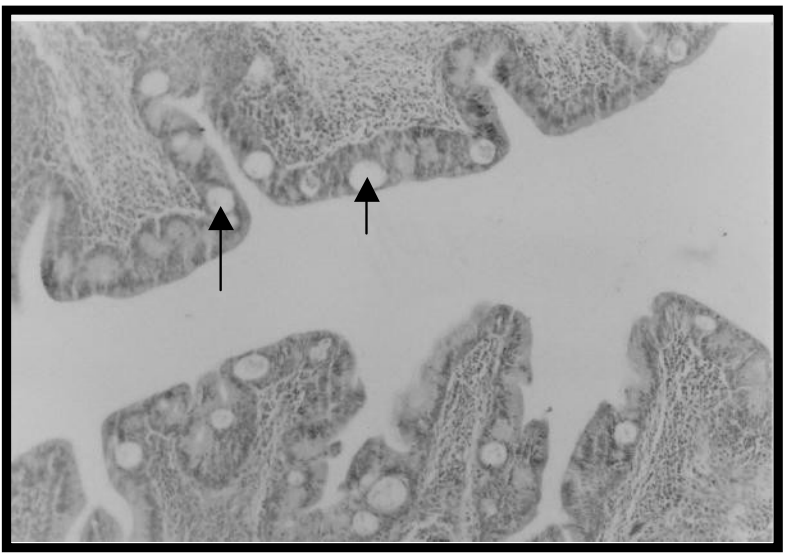

Figura 1: Frango. Bolsa de Fabrício. Numerosos cistos no epitélio de revestimento da prega (seta). H. E obj. 10X

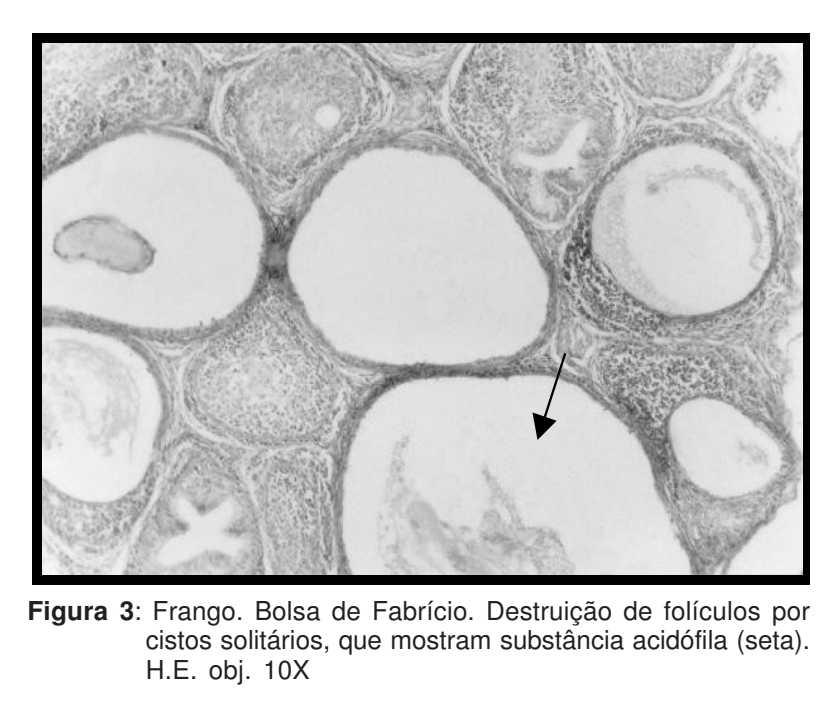

Figura 3: Frango. Bolsa de Fabrício. Destruição de folículos por cistos solitários, que mostram substância acidófila (seta) H.E. obj. $10 \mathrm{X}$
O exame microscópico da bolsa revelou múltiplas alterações de folículos e interstício freqüentemente acompanhadas de cistos no epitélio de revestimento das pregas (Figura 1). As lesões foliculares apresentavam as seguintes características: material fluido fortemente acidófilo entre os elementos linfóides da medular; infiltrado de heterófilos, ora na cortical, ora em todo o folículo, ora no interstício; necrose afetando de poucos a inúmeros folículos; rarefação discreta a intensa dos elementos linfóides (Figura 2); atrofia dos folículos, por vezes com desaparecimento dos elementos linfóides; cistos de diâmetros variados na medular, isolados ou múltiplos, preenchidos, às vezes, com fluido acidófilo (Figura 3). As lesões do interstício eram representadas por fibrose (Figura 4), bem como por infiltração inflamatória de mononucleares e edema. Somente uma ave não apresentou alterações.

As lesões consideradas de extrema gravidade tais como: atrofia severa de folículos, cistos foliculares e epiteliais, e fibroplasia intersticial foram observadas em $77,34 \%$ dos casos (Tabela 1).

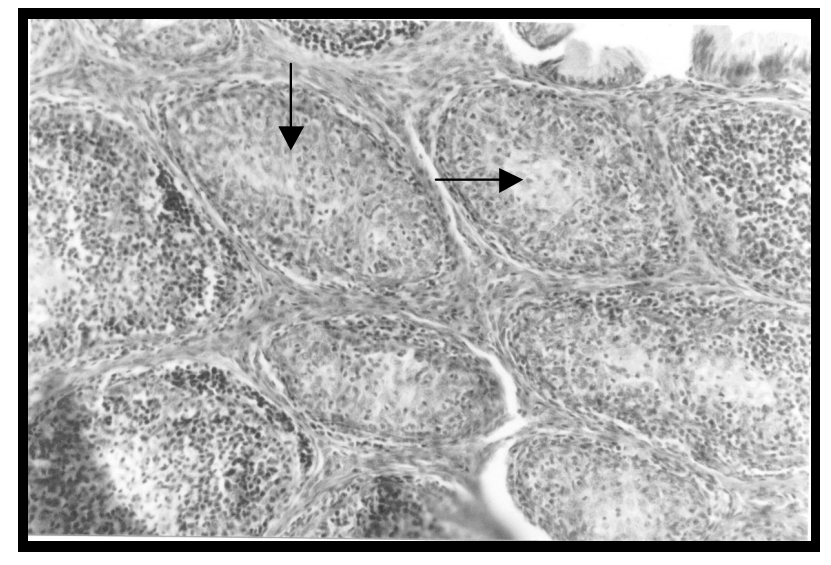

Figura 2: Frango. Frango. Bolsa de Fabrício. Rarefação dos elementos linfoídes dos folículos (seta) envolvidos por fibrose (cabeça de seta). H. E. obj. 20X.

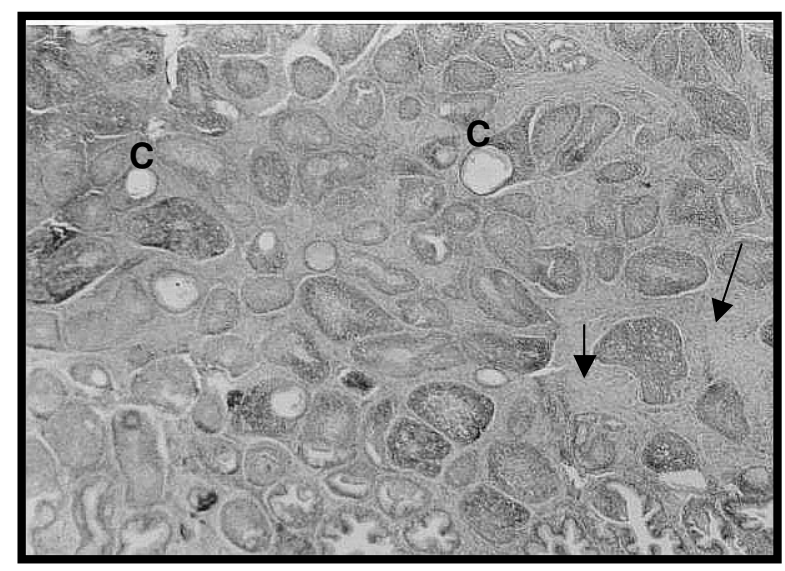

Figura 4: Frango. Bolsa de Fabrício. Aspecto cirrótico do órgão. Nota-se acentuada fibrose (seta), atrofia de folículos (cabeça de seta) e múltiplos cistos foliculares (C). H.E. obj. $4 \mathrm{X}$ 


\section{Discussão}

Tendo em vista que a bolsa de Fabrício é um órgão importante do sistema imune, pois seus folículos contêm mais de $90 \%$ de células B (Tizard, 1998), deve-se supor que as graves lesões, aqui observadas, possam ocasionar imunodepressão, favorecendo assim a ocorrência de múltiplas enfermidades como citado por Rosales (1999), Simon e Ishizuka (2000), Fallavena (2001) e Pereira (2004). Além disso, essas graves lesões microscópicas encontradas no presente estudo, mostraram características semelhantes às descritas na literatura para lesões provocadas pelo vírus da DIB.

A mensuração de bolsas mostrou $42,18 \%$ com tamanho de $10 \mathrm{~mm}$ de diâmetro e 53,12\% com tamanho de $13 \mathrm{~mm}$ de diâmetro, resultados semelhantes aos obtidos por Pereira (2004), que também encontrou elevado percentual (80,76\%) dos casos representados por bolsas nos tamanhos de 10 e $13 \mathrm{~mm}$ de diâmetro, em frangos de corte com idade de abate. Em ambos os estudos, o percentual também foi alto dos escores histológicos 2 e 3, representados por características microscópicas que determinam a diminuição de volume da bolsa de Fabrício.

Pereira et al. (2003) verificaram que $76,96 \%$ dos frangos examinados apresentaram medida no bursômetro compatível com o uso da vacina, resultado diferente do obtido na presente análise, onde menos da metade das bolsas apresentaram alterações compatíveis com a ação do vírus vacinal da DIB.

\section{Referências}

BERNARDINO, A. Controle da Doença de Gumboro - Proposta Fort Dodge. In: II SIMPÓSIO DA DOENÇA DE GUMBORO, 2001, Campinas. Anais....Campinas: FACTA, 2001, p. 143-156.

BOLIS, D.A.;PAGANINI, F.J.;SIMON, V.A.;ZUANAZE, M. F.; SCANAVININETO, H.; CORREA, A. R.; ITO, N. M. K. Gumboro Disease: Evaluation of serological and anatomopathological reponses in vaccinated broiler chickens challenged with very virulent vírus strain. Revista brasileira de Ciência Avícola, Campinas, n. 2, v. 5, maio/agosto 2003, p.137146.

FALLAVENA, L. C. B. Lesões Cutâneas em Frango de Corte: Causas, Diagnóstico e Controle. In: CONFERÊNCIAAPINCO 2001 DE CIÊNCIAE TECNOLOGIAAVÍCOLAS, 2001, Campinas. Anais...Campinas : FACTA, 2001, p. 205-216.

LEFFER, E. V. B.Considerações sobre o controle da doença de Gumboro. Ave world. São Paulo: Animal World, abr./maio 2004. Número especial.

LEY, D. H.; YAMAMOTO, A. B.R.; BICKFORD, A. A. The Pathogenesis of Infectious Bursal Disease: Serologic, Histopathologic and Clinical Chemical Observations. Avian Diseases, v. 27, n. 4, p. 1060-1085, 1983.

MONTASSIER, H. J. Enfermidades do Sistema Imune. In: BERCHIERI JR.; MACARI, M. Doença das aves, FACTA: Campinas, 2000, 800 p, Cap. 2, Item 2.10, p. $133-150,2000$.

PEREIRA, R.;ALLGAYER, M. C.; FALLAVENA, L. C. B.; MORAES, H. L. S.; FITTÉL, A. P.; MOTTA, A. C.; SANTOS,L. R.; SALLE, C. T. P. Doença Infecciosa da Bursa (DIB) - Comparação entre Monitoria por Exame Histopatologico e Bursometria. In: XI ENCONTRO NACIONAL DE
Entretanto, na análise histológica das lesões na bolsa de Fabrício, encontraram $62,76 \%$ dos casos com alterações classificadas no escore mais alto (lesões mais graves), resultado similar ao do presente estudo em que $77,34 \%$ das bolsas foram classificadas no escore 3 .

Bolis et al. (2003) observaram severas lesões nos folículos linfóides em um grupo de aves que não foram vacinadas e em outro, vacinado com cepa intermediária "plus", ambos desafiados posteriormente com cepa muito virulenta do vírus da DIB. As aves do presente estudo que tinham entre 40 e 48 dias de idade, foram vacinadas contra a DIB no $14{ }^{\circ}$ dia de idade e apresentaram lesões microscópicas semelhantes às descritas no estudo citado, o que poderia sugerir uma falha no método de vacinação ou na resposta vacinal, caso fosse confirmada a mesma etiologia.

Os experimentos conduzidos por Ley et al. (1983) e Tanimura et al. (1995) com o vírus da DIB demonstraram uma grande variedade nas lesões observadas na bolsa de Fabrício. Estas lesões também foram encontradas no presente estudo, embora a etiologia não tenha sido elucidada.

\section{Conclusão}

A maioria dos frangos de corte (122) ao abate apresentou os menores tamanhos das bolsas de Fabrício, na escala do bursômetro, conseqüência das lesões microscópicas mais graves, que provocaram a atrofia do órgão, o que pode comprometer a higidez da ave.

PATOLOGIA VETERINÁRIA, 2003, Botucatu. Anais... Botucatu: UNESP, 2003. p. 138

PEREIRA, V. L. A. Qualidade de frangos de corte ao abate pela relação entre peso, doenca de gumboro e algumas enfermidades associadas. Niterói, 2004. 75 f. Tese (Doutorado em Higiene Veterinária e Processamento Tecnológico de Produtos de Origem Animal) - Faculdade de Veterinária, Universidade Federal Fluminense, Niterói. 2004.

POPE C. R. Pathology of lymphoid organs with emphasis on immunosupression. Veterinary Immunopathology, v. 30, p. 31-44, 1991. ROSALES, A. G. Novas Perspectivas no controle de Doenças Virais: Enfermidade de Gumboro. In: CONFERÊNCIAAPINCO 1999DE CIÊNCIA E TECNOLOGIAAVÍCOLAS, 1999, Campinas. Anais... Campinas: FACTA, 1999, p. 67-72.

SIMON, V.; ISHIZUKA, M. Doenças Virais - Doença Infecciosa da Bolsa de Fabrício - DIB. In: BERCHIERI JR.; MACARI, M. Doença das aves, FACTA: Campinas, 2000, 800p, Cap. 5, Item 5.5, p. 301 -314, 2000.

TANIMURA, N.; TSUKAMOTO, K.; NAKAMURA, K.; NARITA, M.; MAEDA, M. Association between Pathogenicity of Infectious Bursal Disease vírus and Viral Antigen Distribution Detected by Immunohistochemistry. Avian Diseases, v. 39, p. 9-20, 1995.

THRUSFIELD MICHAEL. Veterinary Epidemioogy. Second Edition. Blackwell Publishing, 483 p. 1995.

TIZARD, I. A. Os órgãos do sistema imune. In: TIZARD, I A. Imunologia veterinária. 5. ed. São Paulo: Roca, 1998, 545 p. Cap. 8, p. 79-97.

WILSON, T. J.; MITRANGAS, K.; RAMM, H. C.;BOYD, R. I.;WARD, H. A. Response of the chicken bursal stroma to treatment with Cyclosphophamide and IBD virus. Hystophysiology of the Immune System, p. 75-80, 1998. 